\title{
Motility in Normal and Filamentous Forms of Rhodospirillum rubrum
}

\author{
By A. G. LEE AND J. T. R. FITZSIMONS \\ Department of Physiology and Biochemistry, University of Southampton, \\ Southampton $\mathrm{SO}_{9}{ }_{5} \mathrm{NH}$
}

(Received 29 July 1975; revised I6 October 1975)

SUMMARY

By suitable choice of medium, Rhodospirillum rubrum has been grown both in normal (length $2 \mu \mathrm{m}$ ) and filamentous (length up to $60 \mu \mathrm{m}$ ) forms. Both forms were highly motile, and negatively-stained preparations showed bipolar flagellated cells, with an average of seven flagella at each pole. Motion consisted of a series of runs and tumbles, the distribution of run time-lengths being Poissonian. Both forms tumbled in response to dark shock and showed negative chemotaxis to oxygen. The observation that the motility pattern was very similar in normal and filamentous forms makes chemical control of tumbling unlikely and favours a system involving membrane potentials.

\section{INTRODUCTION}

Recently, considerable attention has been focused on the motility of bacteria, as representing a form of cell excitability particularly suitable for experimentation. The propulsion of bacteria has now been firmly attributed to helical rotation of their flagella (Berg, 1974). In peritrichous bacteria such as Escherichia coli and Salmonella typhimurium, it has been established that reversal of the direction of this flagellar rotation is involved in tumbling of the bacteria, and that when bacteria sense changes in the quality of the environment through specific receptors this leads to changes in the frequency of tumbling, resulting in the observed movement towards attractants or away from repellents (Koshland, I974; Silverman \& Simon, 1974; Berg, 1974). Since some twenty chemoreceptors have been identified in $E$. coli, all of which affect bacterial tumbling (Adler \& Tso, 1974), it is likely that some kind of communication system exists to transmit sensory data from the receptors to the flagella, with convergence of signals either before or at the flagella. An essential part of the behavioural response is the so-called 'tumble generator' and the way that this generator is affected by chemoreceptor signals (Berg \& Brown, 1972; Parkinson, 1974). In the monotrichous bacterium Pseudomonas citronellolis, there is no tumbling, but rather the bacterium 'backs-up' briefly before proceeding in a new direction, resulting in a random-walk type of motion (Taylor \& Koshland, 1974). In the bipolarly flagellated bacterium Spirillum volutans, the individual flagella at each pole normally associate to form a relatively thick fascicle; the fascicle at the front is bent back along the length of the bacterium, while that at the rear trails behind. A change in swimming direction of the organism results from a reversal in the direction of rotation, with associated flipping over, of the fascicles. Krieg, Tomelty \& Wells (I967) found that the reversal of the two fiagella bundles is synchronized to within at least $50 \mathrm{~ms}$ and their photographs show that the change in direction is close to $180^{\circ}$, with no marked tumbling.

The synchronous change in direction of the flagella bundles at each end of $S$. volutans is 
of considerable interest. It seems unlikely that the signal for a change in direction could be by diffusion of a trigger molecule to the specialized structures observed in the region of the flagella tufts (Murray \& Birch-Andersen, 1963): the length of the cell is about $50 \mu \mathrm{m}$, so that even a small molecule would require a time of the order of seconds to diffuse from one end of the bacterium to the other. An electrical signalling system would therefore seem more likely.

We report here on some of the characteristics of the motion of the bipolarly flagellated Rhodospirillum rubrum, both in its normal and in its filamentous forms. Clayton (1964) has already reported many studies on this photosynthetic bacterium, showing that it exhibits both phototaxis and chemotaxis.

\section{METHODS}

Rhodospirillum rubrum, strain SI, was cultivated anaerobically under illumination, either in yeast extract $(0.25 \%)$ plus peptone $(0.25 \%)$ at $\mathrm{pH}_{7.2}$, or in the defined medium (after Ormerod) containing $\left(\mathrm{g} \mathrm{l}^{-1}\right)$ : biotin, $\mathrm{x} \cdot 5 \times 10^{-5}$; DL-malate, 4 ; L-glutamate, $\mathrm{I}$; and ammonium sulphate, 0.5 (Bose, 1963). Exponentially-growing bacteria were centrifuged and resuspended twice in the medium of Clayton (I958). The motility of suspensions of $R$. rubrum, prepared as above, was observed in a Helber bacterial counting chamber, with a central well $0.02 \mathrm{~mm}$ deep. Before observation, the preparation was placed in the dark for $30 \mathrm{~min}$ and then illuminated $(60 \mathrm{~cm}$ from a $100 \mathrm{~W}$ lamp) for $10 \mathrm{~min}$. A Zeiss photomicroscope was used, either recording motility tracks on videotape using commercial equipment, or recording tracks photographically on Kodak Tri-X Pan film. For dark-field microscopy a I2 V, 60 W lamp was employed with a cell containing a $\mathbf{I ~} \mathrm{cm}$ thickness of water as a heat filter.

For electron microscopy, suspensions of bacteria on Formvar-coated copper grids were negatively stained with $2 \%(\mathrm{w} / \mathrm{v})$ potassium phosphotungstate $\mathrm{pH} 5.5$ for about $5 \mathrm{~s}$, and were examined in a Hitachi HU-I2 electron microscope.

\section{RESULTS AND DISCUSSION}

\section{Morphology}

Since the work of Van Niel (1944), it has been known that the morphology of R. rubrum is highly variable with respect both to length and shape. In anaerobic cultures in yeast extract plus peptone at $\mathrm{pH} 7 \cdot 2$ we found that most cells (referred to as normal cells) were helical with a single turn, and about $0.5 \mu \mathrm{m}$ wide and 2 to $5 \mu \mathrm{m}$ long. In the defined medium, however, although the cells were still about $0.5 \mu \mathrm{m}$ wide and helical, they were very much longer (typically between ro and $60 \mu \mathrm{m}$ ) with up to ten turns. The formation of these filamentous forms presumably resulted from a delay in division while growth proceeded (Dean \& Hinshelwood, 1966).

Electron micrographs of negatively-stained preparations showed that flagellation was identical in the normal and filamentous forms. The majority possessed flagella at both poles, the typical number of flagella at each pole being seven (Figs. I and 2), with the maximum number observed being ten. Occasional cells were seen with flagella at only one pole: these presumably represented a recent division. The flagella width measured from these phosphotungstate-stained cells was relatively small (II $\mathrm{nm}$ ) compared with a variety of other flagella, even allowing for the fact that phosphotungstate-stained flagella appear to be narrower than those stained with uranate (Cohen-Bazire \& London, 1967). Attachment of the flagella to the cell is shown in Fig. 3, where the hooks at the proximal end of the flagella 

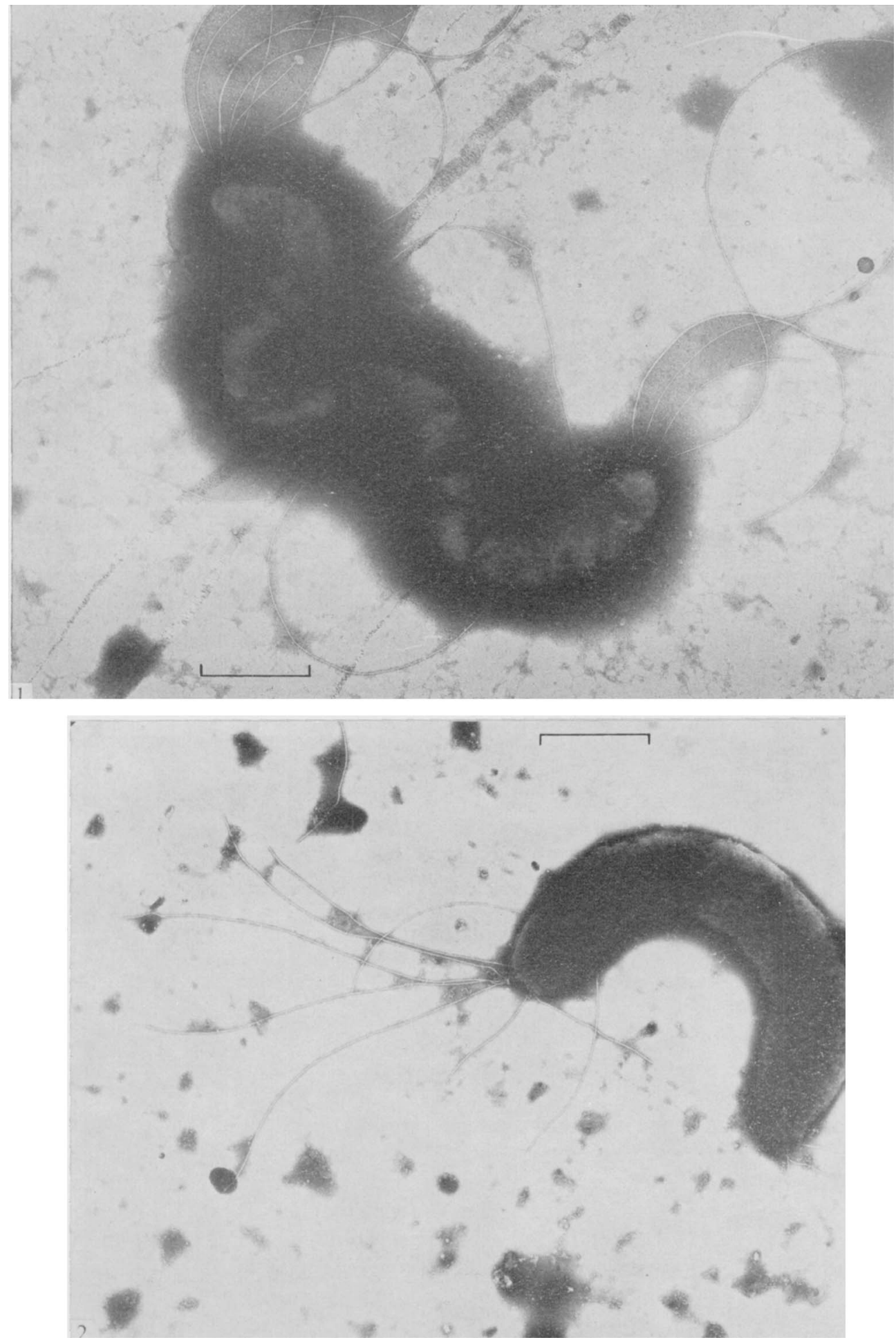

Fig. I. Electron micrograph of a negatively-stained cell of the filamentous form of $R$. rubrum, heavily stained to show the flagella clearly. Bar marker represents I $\mu \mathrm{m}$.

Fig. 2. Electron micrograph of negatively-stained cell of the normal form of $R$. rubrum. Bar marker represents I $\mu \mathrm{m}$. 


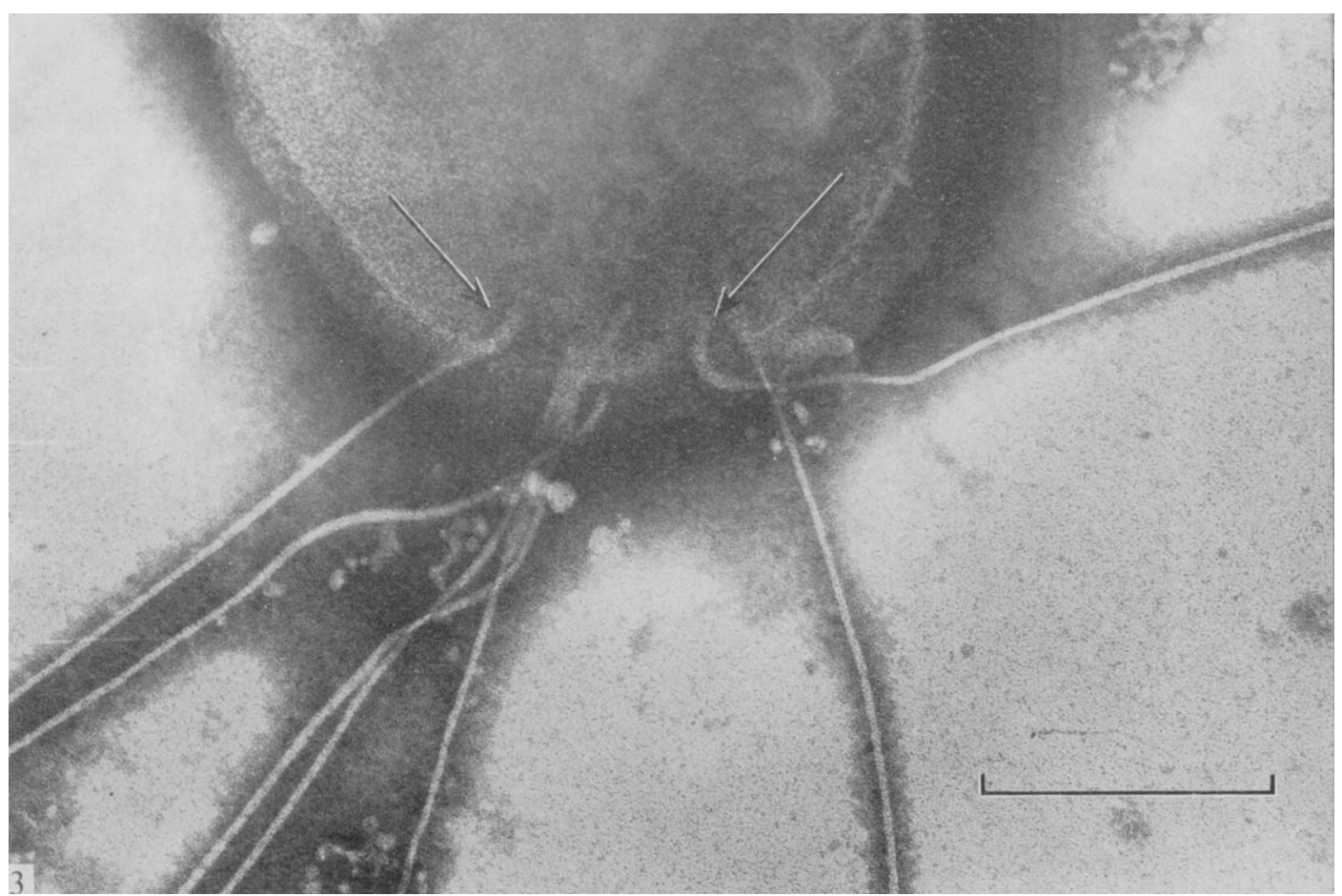

Fig. 3. The left-hand pole of Fig. 2 at higher magnification, showing attachment of flagella. Arrows show basal structures. Bar marker represents $0.25 \mu \mathrm{m}$.

can be seen, together with the basal structures in the cytoplasm. The flagella length was highly variable, the maximum observed being $8 \mu \mathrm{m}$. Part of the variability was probably due to breakage of the flagella occurring either naturally in the culture or during fixation for electron microscopy. Part could also have been due to cell division: thus the bacterium shown in Fig. 2 was probably the result of a recent division, since all the flagella at the righthand pole are considerably shorter than those at the left. The flagella were either straight (Fig. 2) or showed only a gentle curve (Fig. I) as in species of Spirillum (Williams \& Chapman, I96I), rather than having the helical shape typical of other bacteria such as Salmonella (Iino and Mitani, 1966).

\section{Motility of normal organisms}

Either the motion of bacteria was recorded on videotape, or the paths of all the cells in the field of observation were recorded on film as white tracks on a black field using dark-field illumination (Feinleib \& Curry, 1967). One advantage of the videotape system was that it allowed single bacteria to be tracked for a considerable time on the monitor screen, using either the normal or slow-play-back facilities. Another was that it allowed the tracking of all the bacteria present in the field of observation; this is potentially important, because we found that when single bacteria were chosen for tracking, apparently at random, there was in fact a tendency to track only the slowest and fastest moving organisms.

A typical motility track is shown in Fig. 4. The motion is very similar to that described by Berg \& Brown (1972) for E. coli. The bacterium swims in a fairly straight path, then stops, tumbles and moves off in a new direction. Velocities measured from such motility tracks 
Table I. Motility in normal and filamentous Rhodospirillum rubrum and Escherichia coli

\begin{tabular}{lccc} 
& Rhodospirillum rubrum & \\
\cline { 2 - 3 } & $\overbrace{\text { Normal cells }}$ & Filamentous cells & Escherichia coli* \\
Mean speed $\left(\mu \mathrm{m} \mathrm{s}^{-1}\right)$ & $36 \pm 17 \dagger$ & $34 \pm 19 \dagger$ & $14 \cdot 2 \pm 3 \cdot 4 \dagger$ \\
Mean run time-length (s) & $2 \cdot 3 \pm 1 \cdot 7 \dagger$ & $2 \cdot 4 \pm 1 \cdot 8 \dagger$ & $0.86 \pm \mathrm{r} \cdot \mathrm{I} 8 \dagger$ \\
Tumbling time (s) & $\approx 0.2$ & $<0.5$ & $0.14 \pm 0.19 \dagger$
\end{tabular}

* Data from Berg \& Brown (1972). † S.E.M.

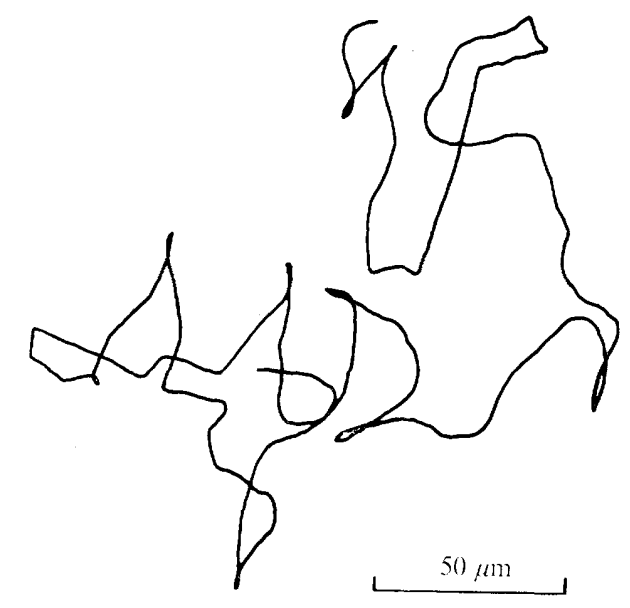

Fig. 4. A typical motility track for $R$. rubrum, over a period of $30 \mathrm{~s}$.

were underestimates, because motion in a direction perpendicular to the surface of the slide was not recorded. This effect would be small, however, both because the thickness of the measuring chamber $(20 \mu \mathrm{m})$ did not allow much vertical movement, and because the depth of focus in dark-field microscopy is sufficiently low for any extensive vertical movement to lead to the disappearance of the organism. The mean speed was $35 \mu \mathrm{m} \mathrm{s}^{-1}$ (Table 1) at $25{ }^{\circ} \mathrm{C}$; this is about twice that of E. coli (Berg \& Brown, 1972; Banks, Schaefer \& Alpert, I 975 ), but well within the range of speeds reported by Vaituzis \& Doetsch (I969) for a wide variety of organisms.

The speed of a particular bacterium remained fairly constant during a run (the period between tumbles; Berg \& Brown, 1972). The end of a run was signalled by the bacterium stopping, after which it appeared to drift for a short period before starting on a new run. Even using slow play-back it was difficult to time this period accurately, but it was estimated to be about $0.2 \mathrm{~s}$. Figure $5 a$ shows a plot of the number of runs of particular time-length, and Fig. $5 b$ shows the data plotted as the logarithm of the number of runs of more than a given time-length. Although the times taken for the individual runs were measured to $0 \cdot I \mathrm{~s}$ the experimental accuracy was less than this, and therefore the data is plotted in the form of the fractional number of runs in time ranges of length $0.5 \mathrm{~s}$. The exponential distribution shown in Fig. $5 b$ shows that the distribution of run time-lengths was Poissonian (Grossman \& Turner, 1974), which means that for a given organism, the probability of a tumble in a given length of time was a constant. This has previously been established for $E$. coli (Berg \& Brown, 1972). 

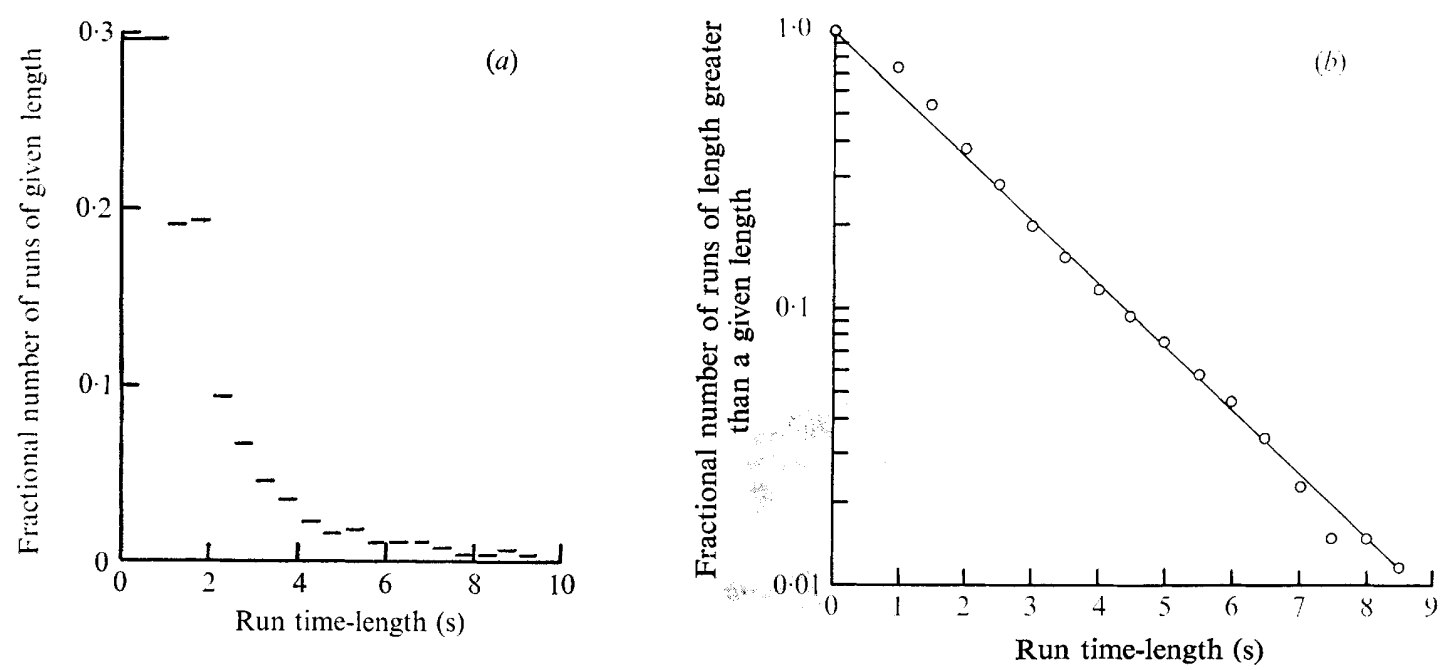

Fig. 5. Analysis of the run time-length in R. rubrum. (a) The fractional number of runs within the time range denoted by the length of one of the lines, is given by the height of that line. (b) The fractional number of runs of time-length greater than a given length is plotted against the given length.

During a run, the motion of the bacterium was analogous to that of a rigid helical screw rotating about its axis, presumably caused by the counter-rotation of flagella. The rate of rotation of the cell body was estimated as 10 rotations/s, both from slow-play-back video recordings and by direct visualization with stroboscopic illumination, varying the flash rate until rotation apparently ceased. Unfortunately, using the present apparatus, it was not possible to visualize the moving flagella clearly (flagella bundles are relatively easy to observe in spirilla, but these bundles probably contain 50 to 100 flagella; Williams \& Chapman, 196I). However, an occasional bacterium was seen rotating while attached to the surface of the microscope slide. The rate of rotation was close to $10 \mathrm{rev} / \mathrm{s}$, and probably reflected the motion of the flagella tethered to the glass surface. The rate of rotation of flagella bundles in $R$. rubrum was probably also close to Io rev./s since, contrary to earlier reports, Caraway \& Krieg (1972) report that in $S$. volutans the rate of rotation of flagella and cell body are identical (I 4 to $27 \mathrm{rev} . / \mathrm{s}$ ).

In $S$. volutans a change in direction of motion is caused by a change in direction of rotation of the flagella bundles (Krieg et al., 1967). The direction of rotation of $R$. rubrum attached to the surface of glass slides was observed to change at intervals of a few seconds, with an equal probability of clockwise or anti-clockwise rotation. The changes in direction probably reflected similar changes in the direction of rotation of the flagella bundles.

When the motion of bacteria was observed by dark-field illumination (see above), mean speeds and the distribution of run time-length measured from such films were identical to those obtained using the videotape recording system, so that neither the more intense light source used in the dark-field technique nor the dark-field optics caused any measurable disturbance to the bacteria.

\section{Motion of filamentous $R$. rubrum}

Motion of the filamentous form of $R$. rubrum was very similar to that of the normal form. The distribution of run lengths obtained either from video recordings or from dark-field 

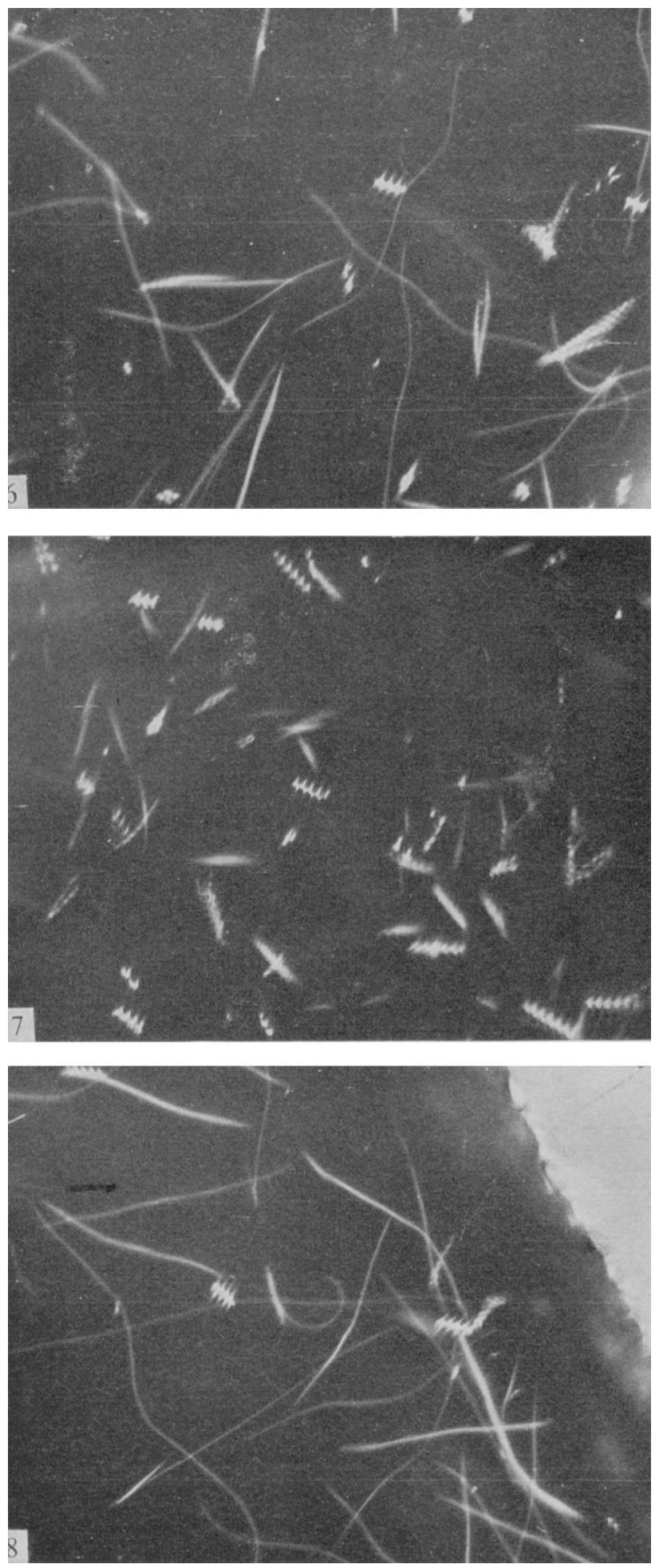

Fig. 6. Motility in filamentous $R$. rubrum. Exposure time $2 \mathrm{~s}$.

Fig. 7. Motility of a sample of filamentous $R$. rubrum during I s, with a $0.2 \mathrm{~s}$ period of darkness after approx. $0.2 \mathrm{~s}$.

Fig. 8. Motility of filamentous R. rubrum in the vicinity of an air bubble. Exposure time $2 \mathrm{~s}$. 
micrographs (Fig. 6) was identical to that shown in Fig. 5 for the normal bacteria. Because of their considerably greater length, there was an increased tendency for the bacteria to stick to the glass slide, making the timing of the period of tumbling rather difficult, but the time of tumbling was certainly less than $0.5 \mathrm{~s}$ and probably identical to that in the normal form. The only significant difference observed was that the mean change in direction between runs for the filamentous bacteria was much closer to $180^{\circ}$ than for the normal forms: this was presumably an inertial effect caused by the long length of the filamentous organisms. The mean speed was not significantly different from that of the normal bacteria (Table $\mathrm{r}$ ).

\section{Dark shock and negative chemotaxis}

It has long been known that many organisms exhibit a shock reaction, consisting of a rapid cessation of movement, following a brief but intense light stimulus (Engelmann, I879). Figure 7 shows the effect a $0.2 \mathrm{~s}$ period of darkness had on $R$. rubrum after a long period ( $15 \mathrm{~min}$ ) of exposure to light. Most of the bacteria reacted by tumbling, and the effect was the same for normal and filamentous forms. Direct observation showed that a small fraction of the bacteria (<I \%) showed no shock reaction even to repeated periods of darkness, and, indeed, showed no apparent tumbling at all, moving continuously in as straight a path as collision with other bacteria allowed. These presumably were mutants of the type that have been isolated for $E$. coli (Parkinson, 1974).

To find whether the filamentous form of $R$. rubrum also showed a normal chemotaxic response, the negative chemotaxis to oxygen (Clayton, 1958) was studied. For both forms, the population density in the vicinity of an air bubble was lower than elsewhere, and in addition, as illustrated in Fig. 8, the run time-length of the bacteria was also increased in the vicinity of the air bubble. Normally, in a 3 s period, only $20 \%$ of the bacteria would travel without tumbling, but in the vicinity of the air bubble this increased to $50 \%$. Further analysis was not possible, because the observed response was an average value for bacteria moving both towards the oxygen and away from it. Berg \& Brown (1972) also observed a net increase in run time-length for $E$. coli, in their case during a positive chemotaxis towards serine.

\section{On the signalling system}

Since both normal and filamentous forms had very similar motility patterns, and both showed phototaxis and chemotaxis, a chemical trigger for tumbling is improbable. Any chemical signalling system would be likely to involve two-dimensional diffusion of the signalling compound within the membrane, for the reasons discussed by Adam \& Delbruck (I968). The rate of diffusion of even a small molecule within the membrane is unlikely to be greater than the rate of diffusion of benzene in a simple lipid bilayer, which is $2 \times 10^{-6} \mathrm{~cm}^{2} \mathrm{~s}^{-1}$ (Rigaud, Gary-Bobo \& Lange, 1972). This means that whereas a chemical signal would take at least $0 . \mathrm{I} \mathrm{s}$ to travel from one end of a $2 \mu \mathrm{m}$ long bacterium to the other, it would take more than $4 \mathrm{~s}$ in a bacterium of length $20 \mu \mathrm{m}$. Since the tumbling time in the filamentous forms of $R$. rubrum was about $0.2 \mathrm{~s}$, a chemical signalling system seems unlikely. A much more rapid response could be obtained by an electrical signalling system. In both Euplotes and Paramecium it has been found that co-ordination of ciliary orientation results from electrotonic spread of spontaneous and evoked membrane potentials (Naitoh \& Eckert, I969; Kung et al., 1975). Tumbling in $R$. rubrum could then be triggered by an increase in the level of $\mathrm{Ca}^{2+}$ for example, in the region of the flagella tufts.

We thank N. Orson for help with the electron microscopy. 


\section{REFERENCES}

AdAM, G. \& Delbruck, M. (I968). Reduction of dimensionality in biological diffusion processes. In Structural Chemistry and Molecular Biology, pp. 198-215. Edited by A. Rich and N. Davidson. San Francisco: W. H. Freeman.

Adler, J. \& Tso, W.-W. (I974). 'Decision'-making in bacteria: chemotactic response of Escherichia coli to conflicting stimuli. Science, New York 184, 1292-I 294.

BANKs, G., Schaefer, D. W. \& AlPERT, S. S. (1975). Light-scattering study of the temperature dependence of Escherichia coli motility. Biophysical Journal 15, 253-26I.

BERG, H. C. (1974). Bacterial behaviour. Nature, London 254, 389-392.

Berg, H. C. \& BROWN, D. A. (1972). Chemotaxis in Escherichia coli analysed by three-dimensional tracking. Nature, London 239, 500-504.

Bose, S. K. (I963). Media for anaerobic growth of photosynthetic bacteria. In Bacterial Photosynthesis, pp. 501-5IO. Edited by H. Gest, A. San Pietro and L. P. Vernon. Ohio: Antioch Press.

CARAWAY, B. H. \& KRIEG, N. R. (1972). Uncoordination and recoordination in Spirillum volutans. Canadian Journal of Microbiology 18, I749-1759.

Clayton, R. K. (1958). On the interplay of environmental factors affecting taxis and motility in Rhodospirillum rubrum. Archiv für Mikrobiologie 29, I89-212.

Clayton, R. K. (1964). Phototaxis in micro-organisms. In Photophysiology 2, pp. 5I-77. Edited by A. C. Giese. New York: Academic Press.

Cohen-BAzIRE, G. \& London, J. (1967). Basal organelles of bacterial flagella. Journal of Bacteriology 94, $45^{8}-465$.

Dean, A. C. R. \& Hinshelwood, C. (1966). Growth, Function and Regulation in Bacterial Cells. Oxford: Oxford Univ. Press.

Engelmann, T. W. (I 879). Physiologie der Protoplasma- und Flimmerbewegung. In Hermans Handbuch der Physiologie, vol. I, pp. 343-408. Leipzig.

Feinleib, M. E. \& Curry, G. M. (1967). Methods for measuring phototaxis of cell population and individual cells. Physiologia plantarum 20, $1085-1095$.

Grossman, S. I. \& Turner, N. E. (1974). In Mathematics for the Biological Sciences, pp. 97-I00. New York: Macmillan.

IIno, T. \& Mitani, M. (I966). Flagella-shape mutants in Salmonella. Journal of General Microbiology 44, $27-40$.

Koshland, D. E. (I974). Chemotaxis as a model for sensory systems, FEBS Letters 40, 53-59.

KRIEG, N. R., TOMELTY, J. P. \& WeLLS, J. S. (1967). Inhibition of flagellar coordination in Spirillum volutans. Journal of Bacteriology 94, I43 I -1436.

Kung, C., Chang, S.-Y., Satow, Y., Van Houten, J. \& Hansma, H. (1975). Genetic dissection of behaviour in Paramecium. Science, New York 188, 898-904.

Murray, R. G. E. \& Birch-Andersen, A. (I963). Specialised structure in the region of the flagella tuft in Spirillum serpens. Canadian Journal of Microbiology 9, 393-40 I.

NAITOH, Y. \& ECKERT, R. (1969). Ciliary orientation: controlled by cell membrane or by intracellular fibrils. Science, New York 166, I633-1635.

PARkinson, J. S. (1974). Data processing by the chemotaxis machinery of Escherichia coli. Nature, London 252, 317-319.

Rigaud, J. C., Gary-Bobo, C. M. \& LANGe, Y. (1972). Diffusion processes in lipid-water lamellar phases. Biochimica et biophysica acta 266, 72-84.

Silverman, M. \& Simon, M. (1974). Flagellar rotation and the mechanism of bacteria motility. Nature, 249, 73-74.

TAYLOR, B. L. \& KoshlAND, D. E. (I974). Reversal of flagellar rotation in monotrichous and peritrichous bacteria: generation of changes in direction. Journal of Bacteriology $119,640-642$.

VAItuzIS, Z. \& DoETSCH, R. N. (I969). Motility tracks: technique for quantitative study of bacterial movement. Applied Microbiology $\mathbf{1 7}, 584-588$.

VAN NIEL, C. B. (I944). The culture, general physiology, morphology, and classification of the non-sulphur purple and brown bacteria. Bacteriological Reviews 8, I-I 8 .

Williams, M. A. \& Chapman, G. B. (I96I). Electron microscopy of flagellation in species of Spirillum. Journal of Bacteriology 8r, 195-203. 